\title{
Thoracoscopic repair of diaphragmatic hernia following ventricular assist device implantation
}

Ryuta Saka ${ }^{1 *}\left(\mathbb{D}\right.$, Takaaki Sakai ${ }^{1}$, Tomomitsu Kanaya ${ }^{2}$, Yuko Tazuke$^{1}$, Yosuke Kugo ${ }^{2}$, Masaki Taira², Takayoshi Ueno ${ }^{2}$ and Hiroomi Okuyama ${ }^{1}$

\begin{abstract}
Background: Diaphragmatic hernia is a rare complication of ventricular assist device (VAD), mainly developing after explantation of the device. We herein report a case of diaphragmatic hernia that developed following the implantation of VAD.

Case presentation: A 4-month-old girl with a diagnosis of dilated cardiomyopathy underwent VAD implantation for a bridge to heart transplantation. Three months later, intermittent vomiting developed, and left-sided diaphragmatic hernia was confirmed on plain X-ray and computed tomography. Without any findings of ischemia, we performed elective thoracoscopic repair of the diaphragmatic hernia. In the right decubitus position, thoracoscopy revealed the small intestine to be herniated into the left thorax. After reduction of the herniated intestine, the defect of the diaphragm $(3 \times 2 \mathrm{~cm}$ in size) was directly closed with interrupted non-absorbable sutures. Her postoperative course was uneventful.
\end{abstract}

Conclusion: Thoracoscopic repair of diaphragmatic hernia associated with VAD implantation may be a safe approach.

Keywords: Diaphragmatic hernia, Thoracoscopy, Ventricular assist device

\section{Background}

Left ventricular assist devices (LVADs) have become popular in children with the advent of the Berlin Heart EXCOR ${ }^{\circ}$ (BHE) VAD (Berlin Heart, Inc., The Woodlands, TX, USA). The BHE VAD provides longterm circulatory support for pediatric patients with severe heart failure, not only functioning as a bridge to transplantation but also facilitating the successful weaning off of a VAD [1]. Although advances in VAD technology and clinical management have resulted in improved outcomes of pediatric heart

\footnotetext{
* Correspondence: saka@pedsurg.med.osaka-u.ac.jp

'Department of Pediatric Surgery, Osaka University Graduate School of

Medicine, 2-2 Yamadaoka, Suita, Osaka 565-0871, Japan

Full list of author information is available at the end of the article
}

failure, VADs are associated with potential risks of neurologic, hematologic, gastrointestinal, and immunologic complications [2].

VAD implantation requires dissection of the pericardium and diaphragm from the anterior chest wall, and diaphragmatic hernia is known to be a complication of VAD. Diaphragmatic hernia complicated with VAD is usually identified after VAD explantation with or without heart transplantation [3]. Thus far, only one case report of diaphragmatic hernia in a patient with an LVAD still implanted has been published [4].

We herein report a pediatric case of left diaphragmatic hernia following BHE LVAD implantation in which thoracoscopic repair was performed.

(c) The Author(s). 2020 Open Access This article is licensed under a Creative Commons Attribution 4.0 International License, which permits use, sharing, adaptation, distribution and reproduction in any medium or format, as long as you give appropriate credit to the original author(s) and the source, provide a link to the Creative Commons licence, and indicate if changes were made. The images or other third party material in this article are included in the article's Creative Commons licence, unless indicated otherwise in a credit line to the material. If material is not included in the article's Creative Commons licence and your intended use is not permitted by statutory regulation or exceeds the permitted use, you will need to obtain permission directly from the copyright holder. To view a copy of this licence, visit http://creativecommons.org/licenses/by/4.0/. 


\section{Case presentation}

A 4-month-old girl showing severe heart failure was referred to our hospital. Echocardiography revealed remarkable dilatation of the left ventricle, severe mitral regurgitation, and a low left ventricular ejection fraction (15\%), and she was diagnosed with dilated cardiomyopathy (DCM). She received temporary LVAD implantation (ROTA flow), followed by exchange to a BHE device. At the implantation of the LVAD, the pericardium and diaphragm were dissected from the anterior chest wall using LigaSure ${ }^{\mathrm{TM}}$ (Medtronic, Minneapolis, MN, USA).

At 7 months of age (body weight, $5 \mathrm{~kg}$ ), she received a surgical consult for intermittent emesis and irritability. Her abdomen was soft, and gurgle was heard at the left chest. Plain X-ray showed suspected intestinal loops in her left thorax (Fig. 1a). Plain chest and abdominal computed tomography confirmed the diagnosis of diaphragmatic hernia with herniation of the small intestine (Fig. 1b). The laboratory findings were normal. Ultrasonography revealed intestinal tracts with maintained blood flow in the left thorax. In the absence of findings of bowel ischemia, an operation was performed electively after decompressing the intestinal tract. Her anticoagulant management was maintained with aspirin, dipyridamole, and warfarin preoperatively. Prior to the operation, the effect of warfarin was reversed with lyophilized human prothrombin complex concentrate (Kcentra ${ }^{\circ}$; CSL Behring, King of Prussia, PA, USA).

Since a transperitoneal approach was not possible due to the blood pump and cannulae just above the abdomen (Fig. 2a), thoracoscopic repair was performed. She was placed in the right lateral decubitus position, and BHE cannulae (inflow and outflow) were fixed to her abdomen (Fig. 2b). Three 5-mm trocars were placed at the midaxillary line at the 7 th intercostal space (ICS), the posterior axillary line at the 8th ICS, and the posterior axillary line at the 10th ICS. Artificial pneumothorax $(5 \mathrm{mmHg})$ using carbon dioxide was established. Following manual reduction of the herniated small intestine using a 5$\mathrm{mm}$ laparoscopic blunt-tip dissector (ETHICON, Bridgewater, NJ, USA), the diaphragmatic defect $(3 \times$ $2 \mathrm{~cm}$ ) was identified just lateral to the cannula (Fig. 3). Although the lateral rim was substantial, the medial and ventral rims were fragile. First, one thread was applied and ligated. Pulling this thread allowed us to find the rim of the orifice and peritoneum. We took care that all stitches pass through the peritoneum in both sides of the defect. The most medial thread partially passed the pericardium (Fig. 4). The most ventral knot was ligated subcutaneously with the aid of a 19-G needle (Lapa-her-closure ${ }^{\circ}$; Hakko, Chikuma, Japan), which has a wire loop to hold and release a thread (Fig. 5). Finally, the defect was closed with 7 interrupted sutures using 2-0 non-absorbable suture materials (Fig. 6). A 10-Fr chest tube was placed through the most caudal incision. Intraoperative bleeding was $1 \mathrm{ml}$.

Her postoperative course was uneventful, and she is waiting for heart transplantation.

\section{Discussion}

Recently, VAD has become a well-established treatment for severe heart failure in children with the advent of the BHE VAD and the refinement of perioperative management methods [2]. BHE, which is a pneumatic paracorporeal device, is the only VAD for

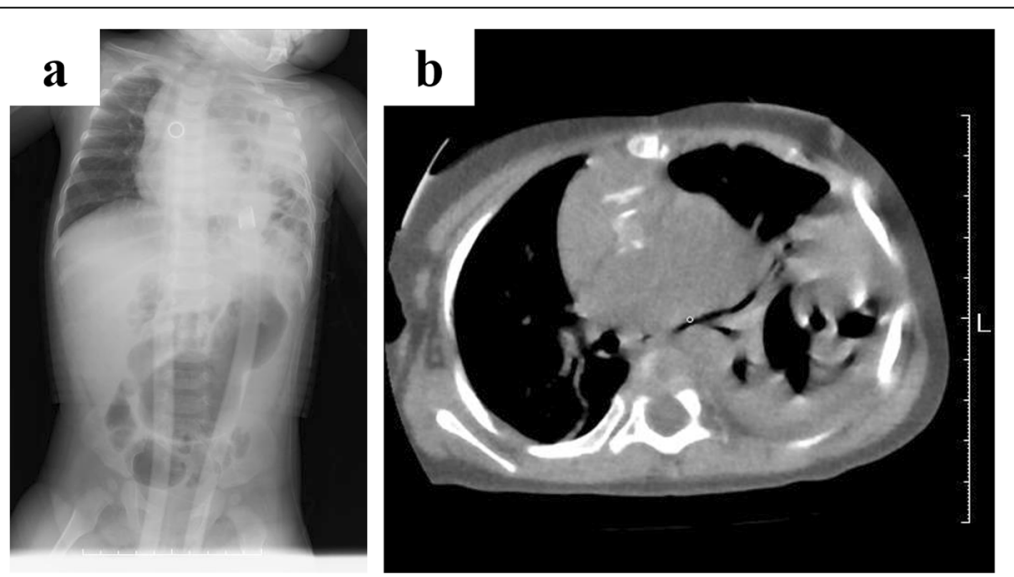

Fig. 1 Preoperative radiological findings. a Plain X-ray shows suspected bowel in the left thorax. $\mathbf{b}$ Computed tomography confirmed diaphragmatic hernia 

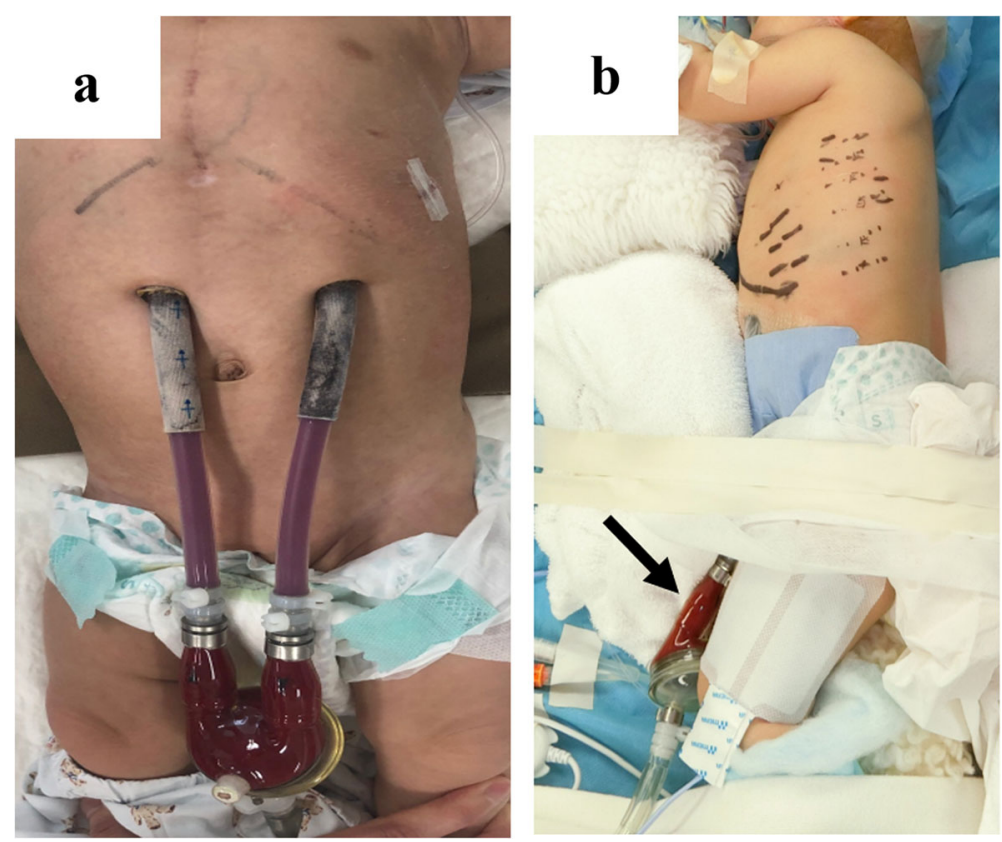

Fig. 2 Patient's abdomen and position. a VAD cannulae were inserted from the upper abdomen. b She was placed in the right decubitus position. The blood pump (black arrow) and cannulae were fixed to her body

small patients [5] and may function as a bridge to transplantation or recovery [6]. The waiting period for heart transplantation is longer in Japan than the global average because of the severe shortage of organ donations for children, so the duration of LVAD implantation may be unavoidably long $[1,7]$.

Diaphragmatic hernia is a potential complication of a VAD due to the need for dissection or penetration of the diaphragm when implanting the device. Although there have been some reports of diaphragmatic hernia following LVAD explantation, most cases have been reported in patients with intracorporeal (intraperitoneal or extraperitoneal) VADs [3, 8-11].
Groth et al. reported that the risk of diaphragmatic hernia is higher after explantation of intraperitoneal LVAD (5.2\%) than with extraperitoneal LVAD (0\%) [8]. Ongele et al. reported the only case of diaphragmatic hernia associated with an implanted LVAD (Heartmate II) treated with robot-assisted repair [4]. This is the first report of diaphragmatic hernia in a patient with an implanted BHE device. In this case, slight damage to the left diaphragm during dissection from the anterior chest wall might lead to the diaphragmatic hernia 3 months later. Attention should be paid to diaphragmatic damage during VAD implantation.
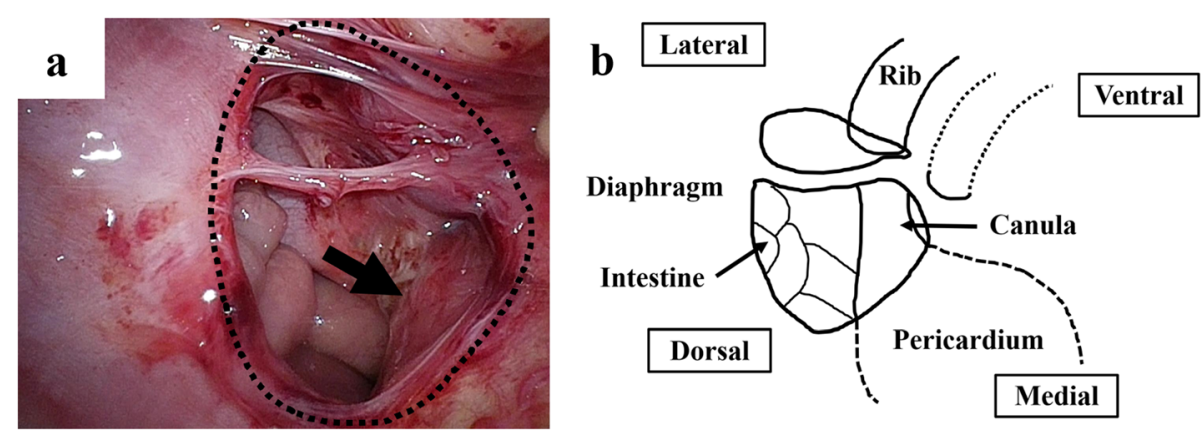

Fig. 3 The orifice of the diaphragmatic hernia and cannula. Following reduction of the herniated small intestine, the diaphragmatic defect (dotted line) was confirmed just lateral to the VAD cannula (black arrow). The defect was $3 \times 2 \mathrm{~cm}$ in size 


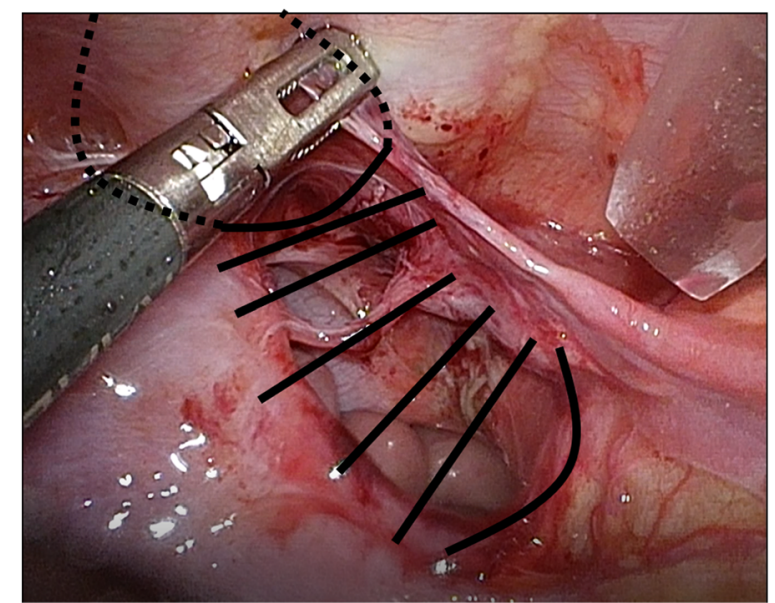

Fig. 4 Schematic illustration of each stitch. The most medial stitch partially passed the pericardium

There are two approaches to repairing diaphragmatic hernia: through the thorax or the abdomen. In our case, the patient had an extracorporeal blood pump and cannulae just above her abdomen. Therefore, we needed to select the thoracoscopic approach, which is often used in cases of congenital diaphragmatic hernia. The advantage of the thoracoscopic approach was that we could enclose the orifice without obstruction by intraperitoneal organs, such as the liver and intestine. In the present case, we were able to complete diaphragmatic hernia repair safely under an excellent thoracoscopic view. While we selected direct closure, most cases of diaphragmatic hernia following explantation of the VAD receive patch repair because the diaphragmatic defect tends to be large $[4,8-10]$. Since it was acquired diaphragmatic hernia, the defect was small enough for direct closure without tension.

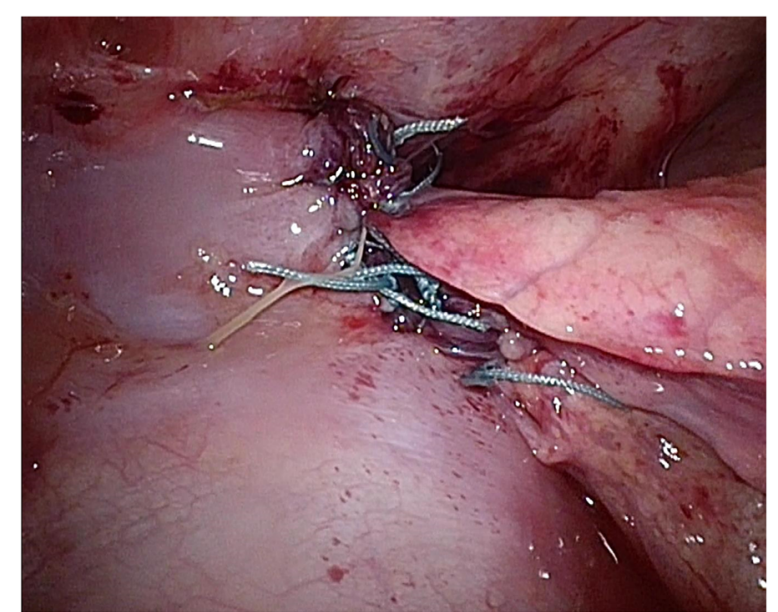

Fig. 6 Closure of the diaphragmatic defect. Using seven nonabsorbable interrupted sutures, the defect was directly closed

In our institute, aspirin, dipyridamole, and warfarin were routinely used for chronic anticoagulation management following VAD implantation. We discontinued the administration of warfarin and reversed the effect with human prothrombin complex concentrate just prior to the operation. Perioperative anticoagulation was managed with the administration of aspirin and dipyridamole with intravenous heparin infusion. Intraoperative and postoperative bleeding was slight with meticulous intraoperative hemostasis. A thoracoscopic approach requires a smaller incision than thoracotomy, resulting in little bleeding.

\section{Conclusions}

Thoracoscopic repair can be a safe and adequate approach to managing patients with diaphragmatic hernia associated with an implanted VAD.
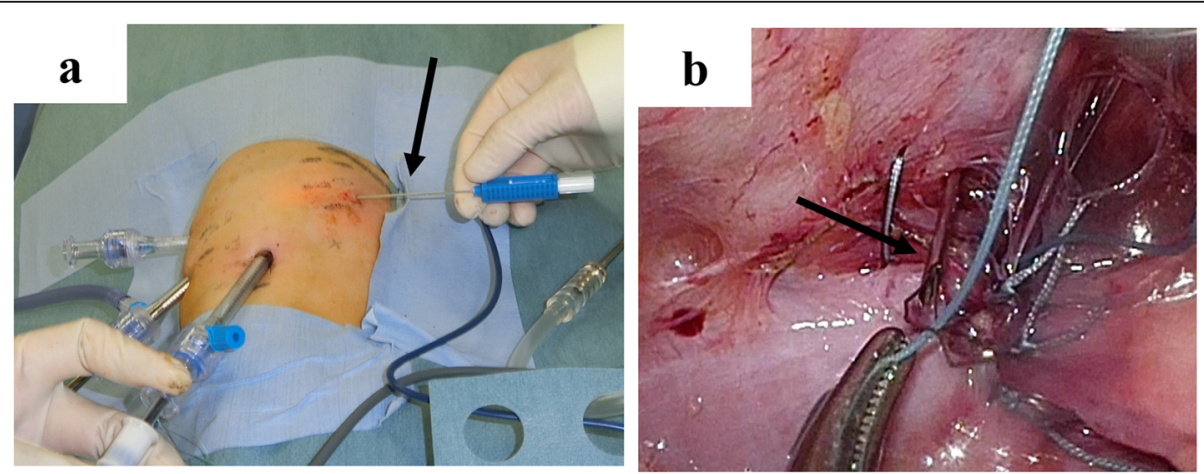

Fig. 5 Trocar settings and ventral closure. a Three 5-mm trocars were inserted in the co-axial setting. Lapa-her-closure ${ }^{\circledast}$ (black arrow) was inserted at the most ventral edge of the diaphragmatic defect. $\mathbf{b}$ The ventral edge of the defect was very slight, so U-shaped sutures were achieved with the aid of Lapa-her-closure ${ }^{\circledast}$ (black arrow) 


\section{Abbreviations}

VAD: Ventricular assist device; DCM: Dilated cardiomyopathy; BHE: Berlin Heart EXCOR ${ }^{\oplus}$

\section{Acknowledgements}

None

\section{Authors' contributions}

RS drafted the manuscript, and $\mathrm{HO}$ supervised the writing of the manuscript. RS, TS, TK, YK, MT, and TU performed the perioperative management of the patient. RS, TS, and YT performed the operation. All authors read and approved the final manuscript.

\section{Funding}

No funding was received for this case report.

\section{Availability of data and materials}

The authors declare that all the data in this article are available within the article.

\section{Ethics approval and consent to participate}

Not applicable

\section{Consent for publication}

Written informed consent was obtained from the parents of the patient for the publication of this report.

\section{Competing interests}

The authors declare that they have no competing interests.

\section{Author details}

'Department of Pediatric Surgery, Osaka University Graduate School of Medicine, 2-2 Yamadaoka, Suita, Osaka 565-0871, Japan. ${ }^{2}$ Department of Cardiovascular Surgery, Osaka University Graduate School of Medicine, Osaka, Japan

Received: 30 May 2020 Accepted: 2 July 2020

Published online: 11 July 2020

\section{References}

1. Kanaya T, Ueno T, Taira M, Kido T, Okuda N, Araki K, et al. Impact of longterm support with Berlin Heart EXCOR ${ }^{\circledast}$ in pediatric patients with severe heart failure. Pediatr Cardiol. 2019;40:1126-33 https://doi.org/10.1007/ s00246-019-02108-0.

2. O'Connor MJ, Rossano JW. Ventricular assist devices in children. Curr Opin Cardiol. 2014;29:113-21 https://doi.org/10.1097/HCO.0000000000000030.

3. Chatterjee S, Williams NN, Lou OM, Twomey C, Morris JB, Acker MA. Diaphragmatic hernias associated with ventricular assist devices and heart transplantation. Ann Thorac Surg. 2004;77:2111-4 https://doi.org/10.1016/j. athoracsur.2003.10.108.

4. Ongele MO, Benrashid E, Gilmore BF, Schroder J, Hartwig M, Zani S. Robot assisted repair of diaphragmatic hernias following ventricular assist device implantation. J Surg Case Reports. 2018;2018:1-3 https://doi.org/10.1093/ jscr/rjy016.

5. Almond CS, Morales DL, Blackstone EH, Turrentine MW, Imamura M, Massicotte MP, et al. Berlin Heart EXCOR pediatric ventricular assist device for bridge to heart transplantation in US children. Circulation. 2013;127: 1702-11 https://doi.org/10.1161/CIRCULATIONAHA.112.000685.

6. Tominaga $\mathrm{Y}$, Ueno $\mathrm{T}$, Kido $\mathrm{T}$, Kanaya $\mathrm{T}$, Narita J, Ishida $\mathrm{H}$, et al. Bridge to recovery with Berlin Heart EXCOR in children $<10 \mathrm{~kg}$ with dilated cardiomyopathy: a histological analysis. Eur J Cardio-Thoracic Surg 2020;0:18. https://doi.org/10.1093/ejcts/ezaa033.

7. Fukushima N, Ono M, Saiki Y, Sawa Y, Nunoda S, Isobe M. Registry report on heart transplantation in Japan (June 2016). Circ J 2017;81:298-303. https://doi.org/10.1253/circj. CJ-16-0976.

8. Groth SS, Whitson BA, D'Cunha J, Andrade RS, Maddaus MA. Diaphragmatic hernias after sequential left ventricular assist device explantation and orthotopic heart transplant: Early results of laparoscopic repair with polytetrafluoroethylene. J Thorac Cardiovasc Surg. 2008;135:38-43 https:// doi.org/10.1016/j.jtcvs.2007.09.017.
9. Farma J, Leeser D, Furukawa S, Dempsey DT. Laparoscopic repair of diaphragmatic hernia after left ventricular assist device. J Laparoendosc Adv Surg Tech - Part A. 2003;13:185-7 https://doi.org/10.1089/ 109264203766207717

10. Ricci KB, Higgins R, Daniels VC, Kilic A. Bovine pericardial reconstruction of the diaphragm after a heart transplant. Exp Clin Transplant. 2014;12:277-8 https://doi.org/10.6002/ect.2013.0068.

11. Phillips WS, Burton NA, Macmanus Q, Lefrak EA. Surgical complications in bridging to transplantation: The Thermo Cardiosystems LVAD. Ann Thorac Surg 1992;53:482-485. https://doi.org/10.1016/0003-4975(92)90273-7.

\section{Publisher's Note}

Springer Nature remains neutral with regard to jurisdictional claims in published maps and institutional affiliations.

\section{Submit your manuscript to a SpringerOpen ${ }^{\circ}$ journal and benefit from:}

- Convenient online submission

- Rigorous peer review

- Open access: articles freely available online

High visibility within the field

- Retaining the copyright to your article

Submit your next manuscript at $\boldsymbol{\nabla}$ springeropen.com 